\title{
CARACTERIZAÇÃO TÉCNICA DE CALCÁRIOS METAMÓRFICOS DE BAIXO CUSTO UTILIZADOS NA DESSULFURAÇÃ̃o DO GÁS DE COMBUSTÃ̃ DO CARVÃO
}

\author{
F. de SOUZA, S. R. BRAGANÇA \\ Universidade Federal do Rio Grande do Sul - Departamento de Materiais \\ E-mail para contato: fabihflor@gmail.com
}

\begin{abstract}
RESUMO - Os calcários têm sido utilizados na captura de SO2 emitido durante a combustão de carvão por décadas. No entanto, devido às complexidades das variáveis envolvidas nesse processo muitas questões ainda estão sendo estudadas. Testes foram realizados em um reator de leito fluidizado, o qual foi utilizado para se avaliar o comportamento do calcário no leito na dessulfuração dos gases de combustão, utilizando-se um carvão de baixo teor de enxofre. Calcários metamórficos dolomíticos de baixo custo, presentes na região sul do Brasil, a qual possui as maiores jazidas carboníferas do país, foram avaliados quanto à eficiência de dessulfuração e caracterizados químico-fisicamente e microestruturalmente. Os dados obtidos foram comparados com um calcário calcítico de maior valor de mercado. Os resultados mostraram pouca influência das impurezas presentes nestes calcários no processo de dessulfuração, fazendo com que os mesmos sejam atrativos a esse processo, embora diminuam a eficiência energética do reator.
\end{abstract}

\section{INTRODUÇÃO}

Calcários e dolomitas são os principais sorventes utilizados na remoção de compostos de enxofre (SOx) emitidos na combustão do carvão mineral na geração de energia. O estudo e a utilização de calcários teve seu interesse renovado tendo em vista a previsão de aumento de consumo de carvão, aumento da capacidade instalada e instalação de novas unidades, como uma termelétrica de leito fluidizado na cidade de Minas do Leão-RS (CRM, 2014; CGTEE, 2014).

A abundância e o baixo custo do calcário explicam sua ampla utilização como meio de se controlar as emissões sulfurosas. Sorventes regeneráveis, considerando-se o custo, ainda não se tornaram competitivos, e seu uso comercial é restrito (Anthony, 2001).

A caracterização de calcários engloba análises químicas e mineralógicas, as quais são muito úteis na diferenciação da composição e dos minerais presentes, entre os diversos tipos de rochas existentes. As propriedades físicas como tamanho de partícula, área específica e volume de poros e a descrição da textura juntamente com técnicas de microscopia são utilizadas na análise dessa matéria-prima. Entretanto, a similaridade entre as propriedades físicas dos minerais carbonatados resulta numa dificuldade na distinção entre eles (Luz, 2005).

Uma caracterização adequada se faz necessária para o melhor entendimento das propriedades mais importantes à dessulfuração. Salienta-se que resultados contraditórios podem ser encontrados na literatura sobre o desempenho de calcários calcíticos e dolomíticos. 
Dependendo das condições experimentais e/ou origem dos calcários a eficiência de dessulfuração, bem como o desempenho do tipo de calcário na dessulfuração pode mudar. É possível se encontrar resultados experimentais em que calcíticos são mais eficientes e outros em que os dolomíticos são melhores (Montagnaro et al., 2002; Kaljuvee et al., 2005; Laursen et al., 2000, de Diego, 2012).

O estudo na oxicombustão tem apresentado interessantes questões sobre o uso de calcários, pois as diferenças na atmosfera de queima dos combustíveis afetam significantemente o processo de retenção de $\mathrm{SO}_{2}$ pelo calcário. Assim, entra em disputa questões como a influência da temperatura de queima, a influência da concentração dos gases e do atrito dos calcários no leito, por exemplo. Além disso, o próprio mecanismo de sulfatação é reavaliado, ocorrendo a sulfatação direta do carbonato e, em temperaturas mais altas, a sulfatação indireta (Montagnaro, 2010; Diego, 2012; Chen, 2012).

A influência das impurezas presentes nos calcários como sílica, sais e óxidos de metais alcalinos na dessulfuração ainda é objeto de dúvidas na literatura, além do desempenho do tipo de calcário referente ao teor de óxido de magnésio, como mencionado anteriormente. Diferentes informações podem ser encontradas. A formação de compostos eutéticos reduz a temperatura de fusão, aumentando a reatividade do calcário, por formação de uma fase líquida, o que provoca uma expansão do poro e aumento da difusão intraparticular (Han, 2005). Por outro lado, a área específica disponível para a reação é reduzida pelo aumento da sinterização (Hu, 2006). Chen (2012) demonstrou que mesmo as impurezas oriundas da combustão de carvão ( $\mathrm{Al}$ e Si) podem ser prejudiciais devido à formação preferencial de eutéticos de aluminossilicato de cálcio.

No presente trabalho são mostrados resultados do uso de calcários dolomíticos em reator de leito fluidizado, comparando-se com um calcário calcítico de maior custo. Como é sabido, calcários dolomíticos não são adequados à indústria cimenteira, portanto, apresentam baixo valor de mercado. A caracterização físico-química dos mesmos foi realizada, procurando-se relacionar as propriedades dos calcários com seu desempenho na dessulfuração. Analisou-se em destaque a performance de um calcário de elevado teor de impurezas. O interesse neste calcário, além da questão tecnológica, é o baixo custo comercial do mesmo, uma vez que o mesmo é run of mine (não beneficiado).

\section{MATERIAIS E MÉTODOS}

Os calcários utilizados neste trabalho, de acordo com um estudo anterior, são oriundos de rochas calcárias metamórficas, podendo ser chamados de mármore-serpentina (Firmino, 1996). Testou-se dois dolomitos (Do e D), um calcário dolomítico (CD), um dolomito calcítico (DC) e um calcário calcítico (C) puro (calcita), provenientes da região sul do Brasil.

Na primeira etapa, faz-se uma avaliação do potencial de utilização do calcário DC com alto teor de impurezas, proveniente da mesma jazida de D e Do, mas sem nenhum beneficiamento, exceto a moagem (run of mine). Este calcário foi estudado em paralelo com o calcário $\mathrm{D}$ beneficiado e com um calcário de elevada pureza (calcário C), a fim de se contrastar as análises de caracterização, de modo comparativo, estudando-se detalhadamente a presença e o tipo de impurezas.

$\mathrm{Na}$ segunda etapa do estudo, desenvolveram-se testes em reator de leito fluidizado (Fundação de Ciência e Tecnologia-RS), utilizando-se os calcários CD e Do, os quais são 
usualmente comercializados. As emissões gasosas foram monitoradas utilizando-se o analisador contínuo por infravermelho (MIR 9000 - émission s.a.).

O carvão utilizado é proveniente da jazida de Candiota (Tabela 1). O reator é escala de bancada de forma cilíndrica com $15 \mathrm{~cm}$ de diâmetro em aço inox, sendo revestido externamente com a lã de vidro. A secção transversal do leito é de $177 \mathrm{~cm}^{2}$ e apresenta uma capacidade de processamento de carvão de $5 \mathrm{~kg} / \mathrm{h}$. As condições experimentais encontram-se resumidas na Tabela 1 . O calcário é misturado com o carvão antes de injeção no reator.

Tabela 1 - Análise do Carvão e condições experimentais do reator

\begin{tabular}{|c|c|l|c|}
\hline Análise imediata (\%) & & Escala do Reator & $\begin{array}{l}\text { Bancada } \\
850^{\circ} \mathrm{C}+/- \\
15^{\circ} \mathrm{C}\end{array}$ \\
\hline Carbono fixo & 25,1 & Temperatura & Areia \\
\hline Voláteis & 18,7 & Material do leito & $177 \mathrm{~cm}^{2}$ \\
\hline Cinzas & 56,2 & Área seção transversal & $15 \mathrm{~cm}$ \\
\hline Análise elementar (\%) & & Altura leito estático & $0.6 \mathrm{~s}$ \\
\hline Carbono & 31,6 & Tempo de residência do gás & $21 \mathrm{~kg} / \mathrm{h}$ \\
\hline Hidrogênio & 2,1 & Vazão de ar & $67 \mathrm{~cm} / \mathrm{s}$ \\
\hline Oxigênio outros & 8,3 & Velocidade do ar & $+/-190 \%$ \\
\hline Nitrogênio & 0,7 & Excesso de ar & $12 \%$ \\
\hline Enxofre & 1,1 & O$_{2}$ gás de exaustão & $2 \mathrm{~kg} / \mathrm{h}$ \\
\hline Umidade & 11,7 & Vazão de carvão & \\
\hline P.C.I.* (kcal/kg) & 2835 & & \\
\hline *P.C.I. Poder calorífico inferior & & & \\
\hline
\end{tabular}

A composição química e mineralógica foi analisada por fluorescência de raios $\mathrm{X}$ (Shimadzu espectrômetro, XRF - 1800) e difração de raios X (Philips X'Pert), respectivamente. Um analisador de tamanho de partículas a laser (Cilas, modelo 1180) foi utilizado para determinação do tamanho de partícula.

Os testes em termobalança (Mettler Toledo modelo TGA / SDTA 851e) foram realizados entre 20-1200 ${ }^{\circ} \mathrm{C}$, com uma taxa de aquecimento de $10{ }^{\circ} \mathrm{C} / \mathrm{min}$ e vazão dos gases $10 \mathrm{~mL} / \mathrm{min}$, em atmosfera de $\mathrm{O}_{2}$ puro, $12 \%$ de $\mathrm{CO}_{2}+$ ar sintético e $80 \%$ de $\mathrm{CO}_{2}+20 \% \mathrm{O}_{2}$.

\section{RESULTADOS E DISCUSSÃO}

\subsection{CARACTERIZAÇÃO DOS CALCÁRIOS COMO MATÉRIA-PRIMA}

A Tabela 2 mostra a composição dos calcários utilizados, na qual se evidencia o alto teor de impurezas de DC e o baixo teor das mesmas em C. A análise das fases por difração de raios X revelou ser o calcário $\mathrm{C}$ principalmente composto por calcita e ausência de dolomita, sendo o teor de outras fases abaixo do teor mínimo de detecção do equipamento, o que está de acordo com a composição química do mesmo (impurezas < 0,7\% e ausência de $\mathrm{MgO}$ ). Os demais calcários apresentaram calcita e dolomita, com a presença de quartzo e de sais de metais alcalinos. A Figura 1 mostra as fases minerais encontradas em DC, mostrando como impurezas a presença de quartzo e argilominerais. 
Tabela 2: Composição química e granulometria dos calcários utilizados Do, $\mathrm{CD}, \mathrm{D}, \mathrm{DC}$ e C

\begin{tabular}{|c|r|r|r|r|r|r|}
\hline Componentes $(\%)$ & Do & \multicolumn{1}{c|}{$C D$} & \multicolumn{1}{c|}{ DC } & \multicolumn{1}{c|}{ D } & \multicolumn{1}{c|}{$C$} \\
\hline $\mathrm{CaO}$ & 29,00 & 42,62 & 35,23 & 37,4 & 56,60 \\
\hline $\mathrm{MgO}$ & 19,52 & 5,61 & 10,93 & 10,53 & - \\
\hline $\mathrm{SiO}_{2}$ & 13,54 & 10,27 & 21,46 & 12,38 & 0,40 \\
\hline $\mathrm{Al}_{2} \mathrm{O}_{3}$ & 0,56 & 1,84 & 2,47 & 1,44 & 0,21 \\
\hline $\mathrm{Fe}_{2} \mathrm{O}_{3}$ & 0,86 & 0,88 & 1,14 & 0,65 & 0,07 \\
\hline $\mathrm{Na}_{2} \mathrm{O}$ & 0,02 & 0,14 & - & - & - \\
\hline $\mathrm{K}_{2} \mathrm{O}$ & 0,08 & 0,74 & 0,51 & 0,36 & 0,04 \\
\hline Outros & 0,08 & 0,18 & 0,11 & 0,04 & - \\
\hline P.F. & 36,18 & 37,42 & 28,16 & 37,20 & 43,20 \\
\hline$\sum$ impurezas* & 15,14 & 14,05 & 25,69 & 14,89 & 0,74 \\
\hline im médio $(\mu \mathrm{m})$ & 35,00 & 41,00 & 44,40 & 48,40 & 42,20 \\
\hline
\end{tabular}

*Obs: demais óxidos sem $\mathrm{CaO}$ e $\mathrm{MgO}$

A Figura 2 mostra a distribuição das impurezas nas partículas calcárias (DC). As impurezas podem ter pouca influência no processo de calcinação/dessulfuração, uma vez que é possível encontrá-las separadas das partículas de calcário, tais quais as partículas de quartzo na Figura 2 b. Este tipo de impureza apresenta bom potencial de serem separadas por processo de moagem, já que são de dureza mais elevada que o calcário, como o quartzo, de modo que tendem a se concentrar como a fração mais grosseira. Por outro lado, a necessidade de removê-las é questionável, pois, em geral, o leito do reator é periodicamente alimentado com areia (ricas em quartzo).

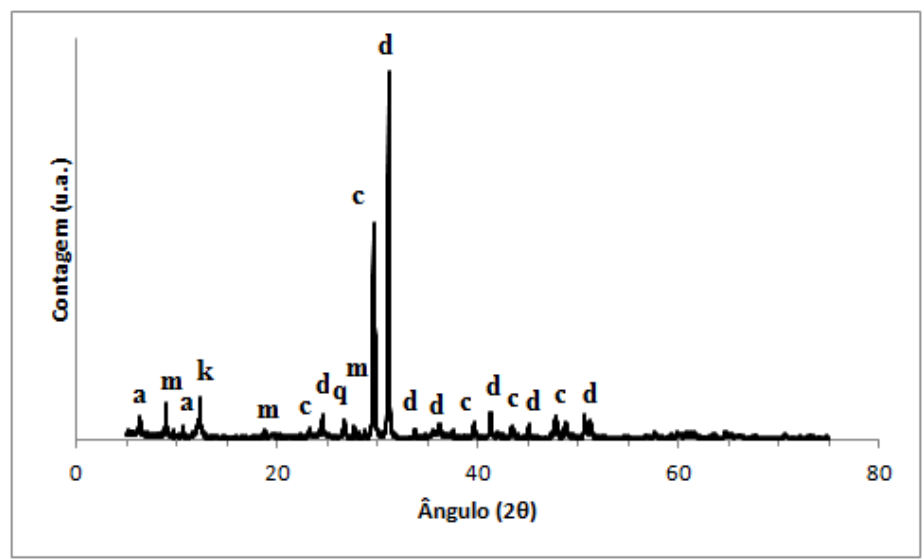

Figura 1 - DRX do calcário dolomito calcítico (DC) in natura. a: argilomineral; c: calcita; d: dolomita; m: muscovita; k: caolinita; q: quartzo

A outra parte das impurezas se encontra na partícula da rocha calcária, mas devem ter pouca influência na calcinação e na dessulfuração, já que estão em contato somente com grãos de calcário no contorno de partícula. Mais importantes seriam as impurezas microcristalinas que podem atuar como fundentes (Chen, 2012) e, potencialmente, prejudicar a eficiência de dessulfuração ou mesmo ter a pouca influência no processo, dependendo das condições operacionais do reator (Anthony, 2001). Este mesmo autor conclui que não há ainda consenso sobre o papel das impurezas na dessulfuração, de modo que é necessária a investigação de caso a caso. 
Portanto, apesar do elevado teor de impurezas presentes em algumas rochas calcárias, como em DC, estas podem ter um bom potencial para utilização na dessulfuração, devido ao menor custo delas, inclusive, dispensando processos de beneficiamento gravimétrico e/ou reciclo em moagem/peneiramento. Salienta-se que estes não removem impurezas inter e intracristalinas.

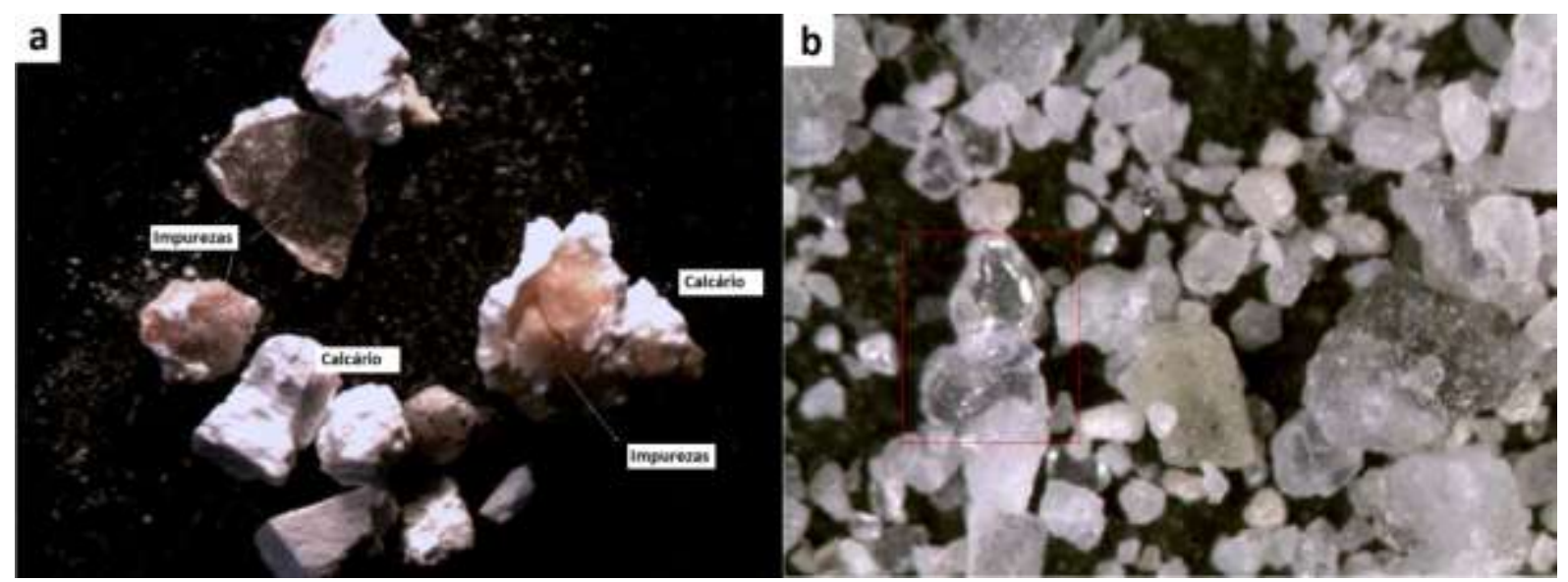

Figura 2 - Análise em lupa eletrônica do calcário DC, mostrando: a) Impurezas separadas das partículas de calcário; b) Partículas de quartzo livres.

\subsection{ANÁLISE EM TERMOBALANÇA}

A análise em termobalança (TG/DTA) foi realizada para as amostras em granulometrias próximas (DC, C e D) em atmosfera de $\mathrm{O}_{2}$ e em diferentes concentrações de $\mathrm{CO}_{2}$. A Tabela 3 fornece as temperaturas de início e término de calcinação e as perdas de massa. Os calcários investigados apresentaram comportamento similar em $\mathrm{O}_{2}$, mas com pequenas diferenças nas temperaturas de início e fim da calcinação. Ao se aumentar a concentração de $\mathrm{CO}_{2}$, é claro o efeito desta no atraso das temperaturas de início e término da calcinação. As perdas de massa para os diferentes calcários se mantiveram aproximadamente constantes nas diferentes misturas gasosas utilizadas, mas em todos os casos foi maior para C (Tabela 3). A menor perda de massa para DC é consequência direta da presença de impurezas, principalmente, aquelas que são inertes à queima, como a sílica $\left(\mathrm{SiO}_{2} \sim 21 \%\right.$; Tabela 2). C mostrou maior concentração de carbonatos, devido à menor quantidade de impurezas na rocha calcária.

Com o aumento da concentração de $\mathrm{CO}_{2}$ na atmosfera para $12 \%$, o principal efeito observado para DC e D foi o aparecimento de um segundo pico endotérmico ligado ao pico endotérmico principal, característicos da descarbonatação da dolomita e da calcita. A separação dos picos entre $\sim 725$ e $925^{\circ} \mathrm{C}$ fica mais evidente ao se aumentar a concentração de $\mathrm{CO}_{2}$ para $80 \%$ (Figura 3). A perda de massa devido à descarbonatação do carbonato de magnésio com $80 \%$ de $\mathrm{CO} 2$ ocorre como um pico constante em $\sim 800^{\circ} \mathrm{C}$; porém, a perda de massa resultante da descarbonatação do carbonato de cálcio resulta em outro pico endotérmico em temperaturas maiores (Figura 3). O aumento da concentração de $\mathrm{CO}_{2}$ resulta em um atraso na temperatura de início da calcinação do $\mathrm{CaCO}_{3}$, mas não do $\mathrm{MgCO}_{3}$, e como consequência os dois picos endotérmicos separam-se cada vez mais. Estudos mais recentes consideram em uma primeira etapa a descarbonatação do $\mathrm{CaMg}\left(\mathrm{CO}_{3}\right)_{2}$, recarbonatação do $\mathrm{CaO}$ e em uma segunda etapa a descarbonatação do $\mathrm{CaCO}_{3}$ (Rodriguez-Navarro, 2012). 
Tabela 3 - Temperaturas de início e término da calcinação e perda de massa em TGA/DTA em diferentes atmosferas de reação

\begin{tabular}{|l|l|c|c|c|}
\hline Amostra & \multicolumn{1}{|c|}{$\begin{array}{c}\text { Condição } \\
\text { experimental }\end{array}$} & \multicolumn{2}{|c|}{ Temperatura de calcinação $\left({ }^{\circ} \mathrm{C}\right)$} & Perda de massa (\%) \\
\hline & $\mathrm{O}_{2}$ & Início & Término & \\
\hline & $12 \% \mathrm{CO}_{2}+$ ar & 384 & 804 & 33 \\
\hline $\mathrm{DC}$ & $80 \% \mathrm{CO}_{2}+\mathrm{O}_{2}$ & 432 & 840 & 32,7 \\
\hline & $\mathrm{O} 2$ & 468 & 918 & 43 \\
\hline & $12 \% \mathrm{CO}_{2}+$ ar & 654 & 828 & 43 \\
\hline $\mathrm{C}$ & $80 \% \mathrm{CO}_{2}+\mathrm{O}_{2}$ & 765 & 882 & 43 \\
\hline & $\mathrm{O} 2$ & 868 & 953 & 36,7 \\
\hline & $12 \% \mathrm{CO}_{2}+$ ar & 564 & 810 & 37,9 \\
\hline $\mathrm{D}$ & $80 \% \mathrm{CO}_{2}+\mathrm{O}_{2}$ & 660 & 860 & 38 \\
\hline
\end{tabular}

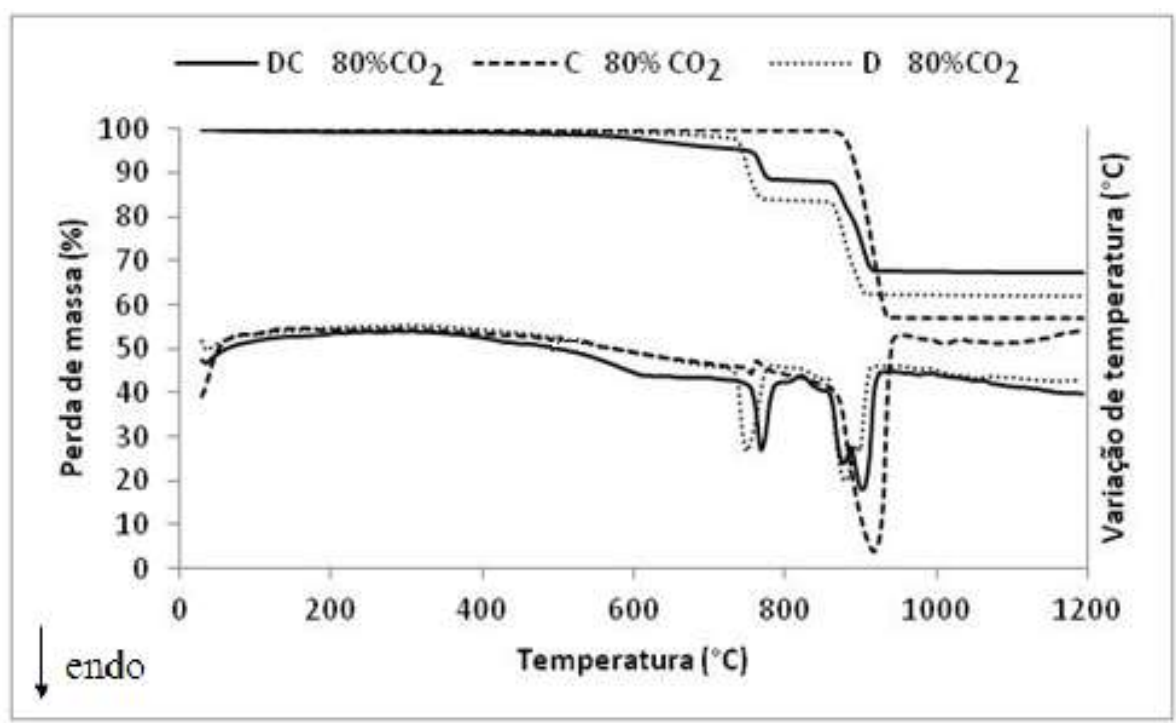

Figura 3 - Curvas TG/DTA para amostras DC, C e D em atmosfera com $80 \% \mathrm{CO}_{2}$.

Portanto, destaca-se que com $80 \%$ de $\mathrm{CO}_{2}$ ocorre a formação de dois degraus na decomposição térmica para DC e D, mas não para C (Figura 3). Assim, em condições oxidantes não há diferenças significativas entre os calcários, porém, em atmosferas ricas em $\mathrm{CO}_{2}$, como na oxicombustão, as diferenças na calcinação devem ser consideradas na determinação da melhor temperatura de dessulfuração, principalmente, quando está em disputa a dessulfuração direta ou indireta. No entanto, vem sendo demonstrado que a sulfatação indireta apresenta mais alta eficiência de dessulfuração, de modo que as temperaturas de operação devam ser acima de $900^{\circ} \mathrm{C}$ (de Diego, 2013). Isto garante a completa calcinação dos calcários, como indicado na Tabela 3.

\subsection{TESTES EM REATOR FLUIDIZADO}

Os resultados dos testes em reator fluidizado (Figura 4) mostram que ambos os calcários (Do e CD) apresentam desempenho semelhante na dessulfuração, alcançando a mesma emissão de $\mathrm{SO}_{2}$ em miligramas por quilocalorias, com o carvão Candiota, para a razão molar 3, sendo possível enquadrar as emissões dentro do padrão mais restritivo das normas ( $2 \mathrm{mg} / \mathrm{kcal}$ ) (CONAMA, 
1991). Neste caso as diferenças composicionais entre os dois calcários não influenciaram no processo de dessulfuração, uma vez que a quantidade alimentada de óxido de cálcio é a mesma, equalizada pela razão molar.

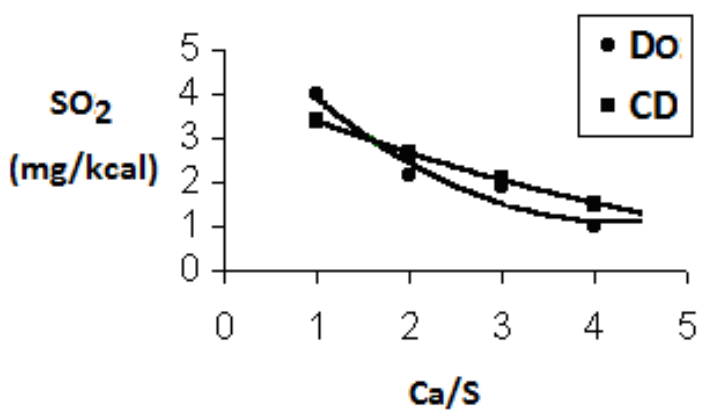

Figura 4 - Emissões de $\mathrm{SO}_{2}$ em função da razão molar do calcário dolomítico (CD) e dolomito (Do).

A principal desvantagem da utilização do dolomito Do é a menor quantidade de óxido de cálcio. Portanto, em base mássica, ele só alcança a mesma eficiência de dessulfuração que CD em maiores quantidade adicionadas do mesmo, aproximadamente, 1,5 vezes a mais. Isso significa 10 toneladas por 100 toneladas de carvão do calcário CD, e 15 toneladas por 100 toneladas de carvão do dolomito. O mesmo deve-se dizer em relação ao consumo energético, considerando-se o calor sensível e o de calcinação (reação endotérmica): Consumo Calórico = Massa de Calcário. (cp. $\Delta \mathrm{T}$ $+\Delta \mathrm{H}$ calcinação). Simplificadamente, tem-se um consumo 1,5 vezes maior ao se utilizar o dolomito.

O custo do dolomito como matéria-prima pode chegar a ser três vezes menor que o dos calcários calcíticos, os quais podem ter custo bastante próximo ao carvão de mineração a céu aberto. Por outro lado, o preço do transporte acaba sendo a variável determinante do custo final e, portanto, da seleção de um calcário. Assim, grosso modo, opta-se por calcários mais próximos às termoelétricas (Anthony, 2001).

\section{CONCLUSÕES}

Os calcários estudados neste trabalho apresentam mesma origem geológica de modo que possuem muitas semelhanças entre si, inclusive com desempenho similar em testes de dessulfuração em combustão do carvão em leito fluidizado. Estes resultados, considerando-se a mesma razão molar $\mathrm{Ca} / \mathrm{S}$ e atmosfera fortemente oxidante, mostraram pouca influência das impurezas e mesmo do teor de óxido de magnésio na dessulfuração, para as condições de realização dos testes.

A caracterização de um calcário de alto teor de impurezas ( 26\%) mostrou que macroscopicamente estas podem estar isoladas ou dividindo uma mesma partícula de calcário. Dessa forma, elas devem interferir muito pouco na dessulfuração, portanto, não há necessidade de removê-las por beneficiamento mineral, podendo-se empregar o calcário nesta forma. Embora o papel de impurezas microcristalinas (intra e intercristalinas) não foi investigado, ressalva-se que estas não são eliminadas por simples beneficiamento.

Os testes de calcinação em termobalança em atmosfera de oxigênio atestam pouca diferença 
na reatividade dos calcários. Para uma concentração de $12 \% \mathrm{CO}_{2}$ (típico de caldeiras) ocorre a calcinação em duas etapas da dolomita, sendo este comportamento mais acentuado em $80 \% \mathrm{CO}_{2}$ (oxicombustão). Neste caso, somente em temperatura mais elevada do que em condições oxidantes a calcinação ocorre de forma completa. Esta ocorreu em cerca de $20^{\circ} \mathrm{C}$ e $30^{\circ} \mathrm{C}$ a menos para os calcários dolomíticos $\mathrm{DC}$ e $\mathrm{D}$, respectivamente, em relação à calcita $\mathrm{C}$. No entanto, a $950^{\circ} \mathrm{C}$ todos calcários estavam $100 \%$ calcinados.

\section{REFERÊNCIAS}

ANTHONY, E. J.; GRANATSTEIN, D. L. Sulfation phenomena in fluidized bed combustion systems. Progr. Ener. Comb. Sci., v. 27, p. 215-236, 2001.

CHEN J., YAO H., ZHANG L., A study on the calcination and sulphation behaviour of limestone during oxy-fuel combustion, Fuel v.102, p.386-395, 2012.

CHEN, Z., GRACE, J. R, LIM, C. J., Limestone particle attrition and size distribution in a small circulating fluidized bed, Fuel, v. 87, p. 1360-1371, 2008.

CRM, CIA Riograndense de Mineração. Disponível em: <www.crm.rs.gov.br>.

DIEGO, LF et al. Optimum temperature for sulphur retention in fluidised beds working under oxy-fuel combustion conditions. Fuel, v.114, p. 106-113, 2013.

HAN K., Lu C., CHENG S., ZHAO G., WANG Y., ZHAO J., Effect of characteristics of calcium-based sorbents on the sulfation kinetics. Fuel, v.84, p.1933-39, 2005.

KALJUVEE, T., TRIKKEL, A., KUUSIK, R., BENDER, V., The role of $\mathrm{MgO}$ in the binding of SO2 by limecontaining materials, Jour. Ther. Anal. Cal., vol. 80, no. 3, p. 591-597, 2005.

LAURSEN, K., DUO, W., GRACE, J. R., LIM, J., Sulfation and reactivation characteristics of nine limestones. Fuel, vol. 79, p. 153-163, 2000.

LUZ, A. B, LINS, F. A. F., Freitas, Rochas \& minerais industriais: usos e especificações. Centro de Tecnologia Mineral, Rio de Janeiro, 2005.

MONTAGNARO, F., SALATINO, P., SCALA, F., The influence of temperature on limestone sulfation and attrition under fluidized bed combustion conditions. Exp. Therm. Fluid Sci., v.34, p.352-358, 2010.

RODRIGUEZ-NAVARRO, C., KUDLACZ, K. RUIZ-AGUDO, E., The mechanism of thermal decomposition of dolomite: New insights from 2D-XRD and TEM analyses. Amer. Miner., v. 99, 38-41, 2012. 